\title{
THERIOGENOLOGY
}

\section{FOLLICULOGENESIS IN THE BOVINE ${ }^{1}, 2$}

\section{R. B. Stalgmiller}

U. S. Department of Agriculture, Agricultural Research Service, and Montana Agricultural Experiment Station, Miles City, MT 59301

and

B. G. England

Department of Pathology, University of Michigan, Ann Arbor, MT 48109

Introduction

One of the key steps in successful embryo transfer is the ability to obtain a controlled rate of superovulation. Pituitary extracts and a wide variety of gonadotropin or gonadotropin-like preparations have been used in an equally wide variety of injection schemes to achieve this goal. While superovulation is obtained from almost all means that have been trled, for the most part it has been far from controlled; and the variation in response to any one scheme has been tremendous. This variation clearly points out the need for a greater understanding of factors contributing to, or inhibiting, the development of follicles both in size and in physiological function. As a result, studies in our laboratory have changed from developing superovulation procedures to a more basic approach of describing normal follicle function and examining factors controlling those functions.

This paper will discuss the physiological characteristics of follicles at the time of behavioral estrus. Further, it will examine follicular development in an estrous synchrony model to study the progression of size and steroldogenic function as selection of the ovulatory follicle approaches. This discussion is by no means intended to be an exhaustive or even an intensive review of the i1terature; rather, it is an attempt to put studies conducted at our research station into the context of our present understanding of folliculogenesis in the bovine.

\section{Experimenta1}

\section{Size and function of the largest follicle}

There is general agreement that the ovulatory follicle ranges in slze from as low as $10 \mathrm{~mm}$ in diameter to about $20 \mathrm{~mm}$ in diameter.

1 This work was conducted at the Livestock and Range Research Station, Miles City, Montana. Publication has been approved by the Director of the Montana Agr. Exp. Sta., Journal Series No. 1237.

2 Appreciation is expressed to NIH, Upjohn Company, and Dr. Gordon Niswender for the the generous provision of radioimmunoassay matertals which helped make these studies possible. 


\section{THERIOGENOLOGY}

From day 4 or 5 of the estrous cycle on to ovulation, there is usually at least one follicle within this size range present on the ovary at all times $(1,2,3,4)$. There is evidence that this single large follicle $\left(F_{1}\right)$ plays a major role along with the corpus luteum in controlling the development and activity of other follicles.

Past reports in swine (5) and sheep (6), as well as in cattle (7), have shown the ovary bearing the corpus luteum (CL) to have greater follicular development than the non-CL ovary. Evidence from our laboratory has shown that on days 8 and 12 , the $F_{1}$ is larger when located ipsilateral to the $C L$ than when contralateral to the CL. In direct contrast to this, a recent report (4) has shown that on days 8 and 13 of the cycle the $F_{1}$ tends to be larger on the non-CL than on the CL ovary. Any local effect of the corpora lutea on follicle development is undefined at this time.

Studies in our laboratory utilizing unilateral ovariectomy have shown that the largest follicle on a pair of ovaries influences development of remaining follicles. If the ovary bearing the $F_{1}$ is removed, it is followed by an increase in follicular size and follicular fluid weight on the remaining ovary 4 days later. If the ovary contralateral to the $F_{1}$ is removed, there is no change in follicular development on the remaining ovary. This effect has been shown between days 4 and 8 and and between days 8 and 12 of the cycle. These results can be interpreted as showing a systemic inhibition of follicular development by the $F_{1}$. The endocrine mechanisms involved in this inhibition have not been defined.

The fate of the $F_{1}$ follicles from mid-cycle on has been shown rather convincingly to be that of atresia and degeneration. Only those $F_{1}$ follicles present very near the onset of behavioral estrus ovulate and form a functional CL (4). Large follicles marked prior to this time have undergone rapid degeneration and have been replaced at ovulation by a follicle which was less than 5 in diameter as recent as $96 \mathrm{~h}$ earlier. There is evidence that during the final segment of the follicular phase there is a turnover of the largest follicle with both the development of a new $F_{1}$ and the degeneration of the prior $F_{1}$ being relatively rapid. This appears to be the reverse of the situation seen early in the cycle when $80 \%$ of the largest follicles on day 3 were still the largest follicles 5 days later (4).

It is likely that the physlological function of the $F_{1}$, particularly in terms of estrogen production, is quite different at estrus than at other times of the cycle. This function of the $F_{1}$ has been examined in detali in our laboratory. Evidence from marked follicles indicates that at the time of behavioral estrus the $F_{1}$ is the ovulatory follicle. Estradiol-17 $3\left(E_{2}\right)$ secretion was determined by in vitro Incubation of follicles isolated either during the preovulatory surge of LH or after the LH concentration had returned to baseline following the surge. 


\section{THERIOGENOLOGY}

The $F_{1}$ follicle secreted $E_{2}$ into the incubation medium (figure 1) at a rate of two to three orders of magnitude greater than any other follicle present in the ovary (8). Furthermore, as in the sheep (9), the occurrence of the ovulatory surge of LH caused a five to 10-fold decrease in the rate of $E_{2}$ secretion in vitro. When the follicles were removed during the LH surge, there was a significant negative correlation between $E_{2}$ secretion and the highest concentration of LH to which the follicle had been exposed prior to ovariectomy (8). The correlation was not significant in cows ovariectomized after the LH surge.

There was no significant correlation between diameter of the $F_{1}$ and secretion of $E_{2}$ in vitro. This should not be surprising since the rapid changes in LH concentrations during this brief period of time, with its effect on $E_{2}$ secretion, could easily mask more subtle changes in $E_{2}$ resulting from follicle size per se.

Receptors were quantitated for LH in both theca and granulosa cells (figure 2) and for FSH in granulosa cells of the $F_{1}$. Both thecal and granulosa cells contained more LH receptors in the cows ovarfectomized during the LH surge than after the LH surge. However, there were no differences in FSH receptors. Secretion of $\mathrm{E}_{2}$ in vitro was significantly correlated with binding of HCG to thecal cells, as were basal LH concentrations. These correlations were computed across all cows, however; and when computed within the LH surge and post-LH surge groups, the correlations were not significant.

Eight follicles, other than the $F_{1}$, were removed from the ovaries of each cow and incubated in vitro to determine $E_{2}$ secretion rates. There was no significant correlation between follicle size and $\mathrm{E}_{2}$ secretion by these follicles, efther computed within-cow or across all cows. Close examination of these elght smaller follicles failed to produce any evidence that there is a second follicle other than the $F_{1}$ with an advantage over the rest of the follicle population in efther size or ability to secrete $E_{2}$. This is interpreted to mean that at this time no other follicle has been "selected" to develop on to ovulation if the $F_{1}$ becomes atretic, is destroyed, or for any reason does not ovulate.

Development of ovulatory follicles

The ovulatory follicle has been identifled as having two dominant characteristics. It is the single follicle secreting large amounts of $\mathrm{E}_{2}$ at the time of behavioral estrus. In sheep (10), it is also exclusively ovulatory follicles that have LH receptors in granulosa cells, and it is probably safe to assume the same is true in cattle. The further task that remains then is to define the time course of events leading to the selection of the ovulatory follicle and the development of these two dominant characterístics. 


\section{THERIOGENOLOGY}

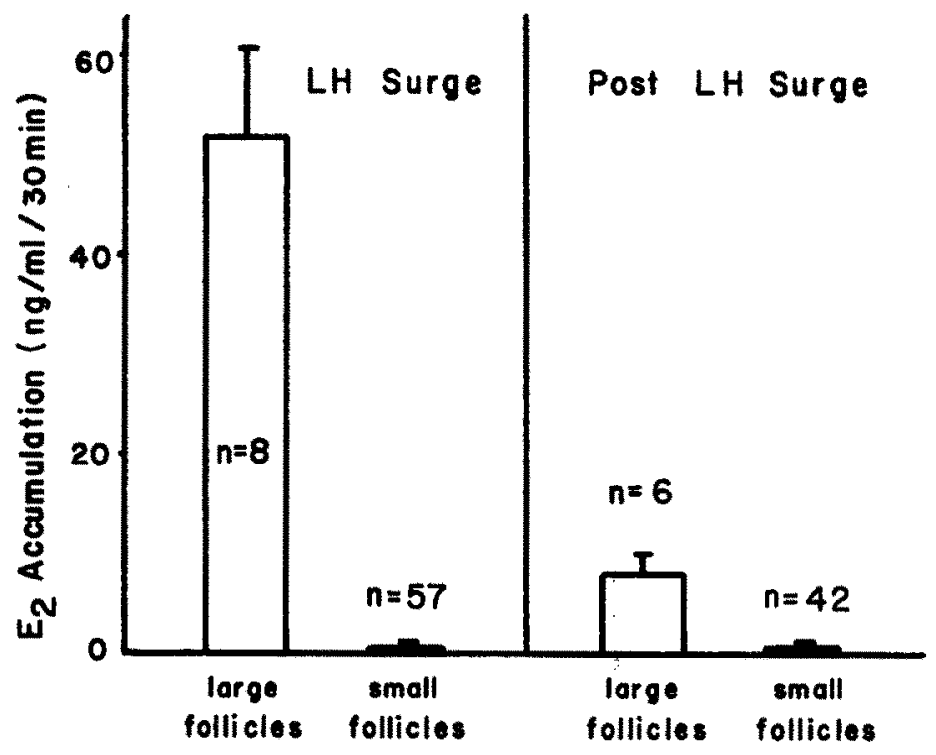

Figure 1. In vitro $E_{2}$ accumulation by individual

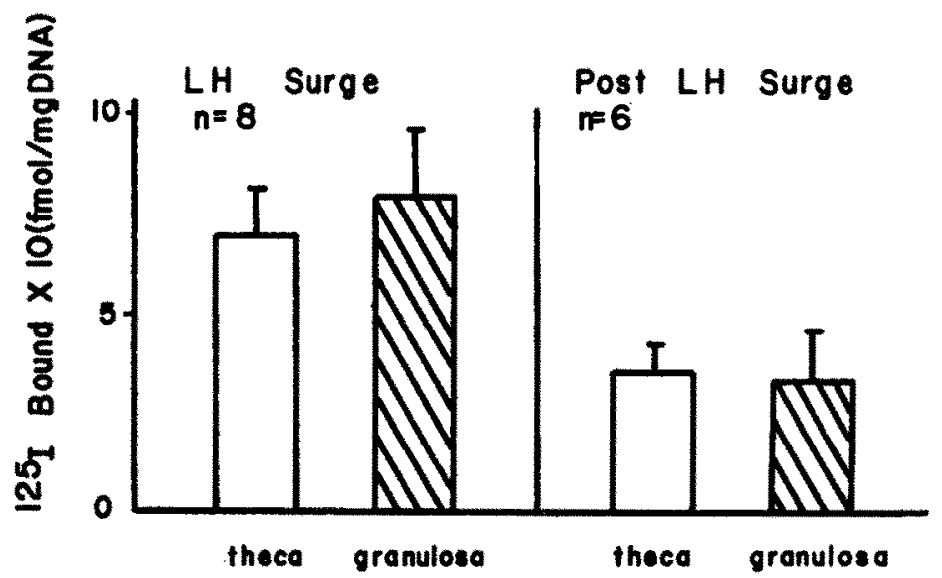

Figure 2. hCG binding to theca and granulosa cells. 
In cattle, length of the estrous cycle can vary as much as 5 to 6 days; yet the rise and fall of an $F_{1}$ follicle appears to occur more rapidly than this near the end of the follicular phase of the cycle. For this reason, it was necessary to obtain a more controlled timing sequence of follicular development than exists in cows showing normal estrous cycles. A synchronlzed model was used for the following study involving a progestin implant for 7 days with an injection of $\mathrm{PGF}_{2} \alpha$ on day 6 of the implant. At implant removal (IR), one-half of the cows had all follicles greater than 5 to $6 \mathrm{~mm}$ in diameter destroyed by electrocautery (cautery). The other half remained as controls. Ovaries were removed via laparotomy and all follicles greater than 3 $\mathrm{mm}$ in diameter were isolated from both cauterized and control cows at 48,72 or $96 \mathrm{~h}$ after implant removal, as well as from one group of control cows at the time of implant removal.

Changes in the follicle population to $96 \mathrm{~h}$ are shown in figure 3. Small follicles from 3 to $5 \mathrm{~mm}$ in diameter remain relatively constant from IR until $96 \mathrm{~h}$ in the control animals. In cautery cows, small follicles increased over twofold from IR to $48 \mathrm{~h}$ but then decreased rapidly to control values in the next $48 \mathrm{~h}$. Medium follicles from 5.1 to $10 \mathrm{~mm}$ in diameter decreased in control antmals from IR to $48 \mathrm{~h}$, remained low unt $1172 \mathrm{~h}$, then increased rather dramatically by $96 \mathrm{~h}$. Most of the control cows had shown an ovulatory surge of $\mathrm{LH}$ prior to $72 \mathrm{~h}$ after IR. The increase in number of medium follicles by $96 \mathrm{~h}$ could be a result of the sharp decline in

$E_{2}$ production which occurs commensurate with the Lit surge, or it could be attributable to some unknown correlated endocrine event. In cautery cows, medium follicles increased slowly up to $48 \mathrm{hr}$ then increased rapidly by $72 \mathrm{~h}$ and decreased again by $96 \mathrm{~h}$. The increase at $72 \mathrm{~h}$ may reflect continued growth of the large number of small follicles seen $24 \mathrm{~h}$ earlier and may indicate an increase in follicular development due to destroying the physiological function of the $F_{1}$. Large follicles greater than $10 \mathrm{~mm}$ in diameter were more abundant at IR than at any other time, averaging almost two large follicles per cow. In control cows, this was reduced to a single follicle by $48 \mathrm{~h}$ and maintained at that level throughout the $96 \mathrm{~h}$. In the cautery cows, only one cow in each of the 48-,72- and 96-h groups had regrown a follicle to greater than $10 \mathrm{~mm}$.

A further indication of follicular function was obtalned by quantitating $E_{2}$, testosterone and progesterone in follicular fluid. Figure 4 depicts the concentrations of these sterolds in large and medium-sized follicles. High concentrations of $E_{2}(>500 \mathrm{ng} / \mathrm{ml})$ were found only in large follicles, but not all large follicles had high concentrations. Cows with more than a single large follicle did not have more than one contalning high concentrations of $\mathrm{E}_{2}$. Stmilar results were reported at estrus when only a single follicle was capable of secreting large amounts of $E_{2}$ in vitro. 


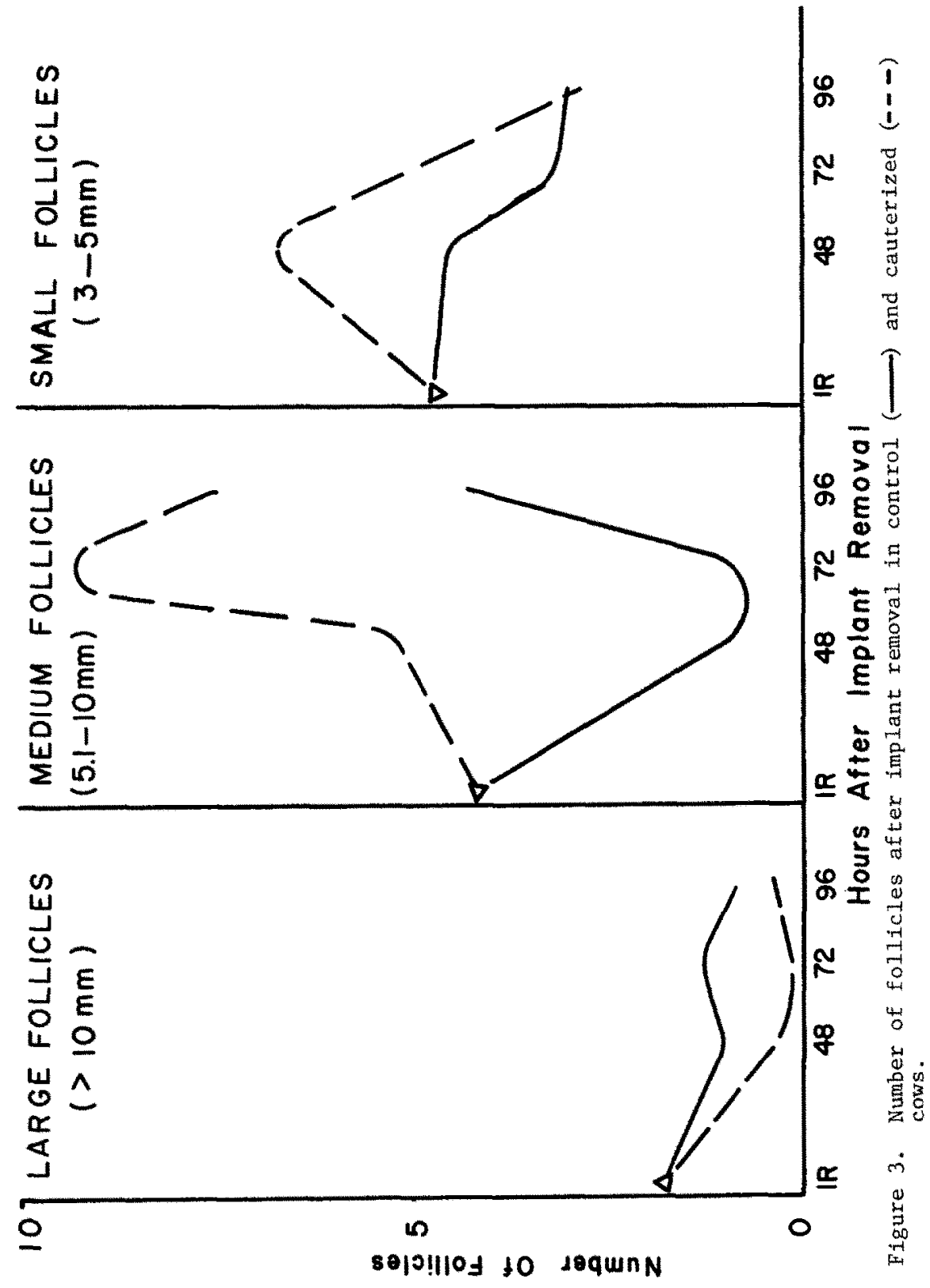


Concentrations of $E_{2}$ at IR were not as high as at 48 and $72 \mathrm{~h}$ after IR. The high concentrations in control cows at 48 and $72 \mathrm{~h}$ almost certainly represents follicles selected for ovulation. At $96 \mathrm{~h}$ after IR, most control cows had shown a preovulatory surge of LH and several had ovulated. Cows showing a preovulatory surge of LH but not ovulating had greatly reduced $\mathrm{E}_{2}$ concentration in the single large follicle but showed greatly elevated concentrations of progesterone. Concentrations of testosterone were low throughout all time periods in control cows.

Only very few large follicles were present in cautery cows; but in contrast to control cows, $E_{2}$ concentrations did not increase until between 72 and $96 \mathrm{~h}$ after implant removal. The rise in $\mathrm{E}_{2}$ was preceded by a large rise in testosterone between 48 and $72 \mathrm{~h}$. Apparently, the mechanism for aromatization follows the ablilty to synthesize testosterone by approximately 24 to $48 \mathrm{~h}$. Progesterone remained low unt1l $72 \mathrm{~h}$ in these follicles then increased slowly commensurate with the $E_{2}$ increase in cautery cows.

Concentrations of $E_{2}$ in the medium follicles of all cows were low at implant removal, remained low until $48 \mathrm{~h}$ and increased slightly by $72 \mathrm{~h}$ and $96 \mathrm{~h}$. Destruction of follicles by electrocautery at implant removal resulted in higher $E_{2}$ concentrations in medium follicles at. all times than those found in control cows. The lack of $E_{2}$ secretion by medium follicles is probably not due to lack of a precursor since testosterone levels were elevated at $48 \mathrm{~h}$ in both control and cautery cows. However, testosterone in control cows showed both higher concentrations at $48 \mathrm{~h}$ and dropped to lower concentrations at $72 \mathrm{~h}$ than in the cautery cows.

The most obvious difference between medium follicles of the control and cautery groups was the difference in the combined total of the three steroids at 48 and $72 \mathrm{~h}$ after IR. The overall steroidogenic capacity of medium follicles in cautery cows did not appear to be as great as in control cows. It must be remembered, however, that most of the medium follicles at IR were destroyed by cautery and the medium follicles recovered at $96 \mathrm{~h}$ would represent recent growth from the sma11 follicle size range. Prior studies have shown that greater than $50 \%$ of the follicles of this size range in a normal cycling cow are atretic $(1,2)$. Possibly, the difference in steroidogenic capacity of the medium follicles between control and cautery cows can be explained on the basis of a grossly different ratio of normal to atretic follicles which was brought about by the rapid growth of small follicles after cautery.

\section{Discussion}

Results of this last study indicate that it requires longer than $96 \mathrm{~h}$ for follicles to develop from approximately $5 \mathrm{~mm}$ in diameter to 


\section{THERIOGENOLOGY}

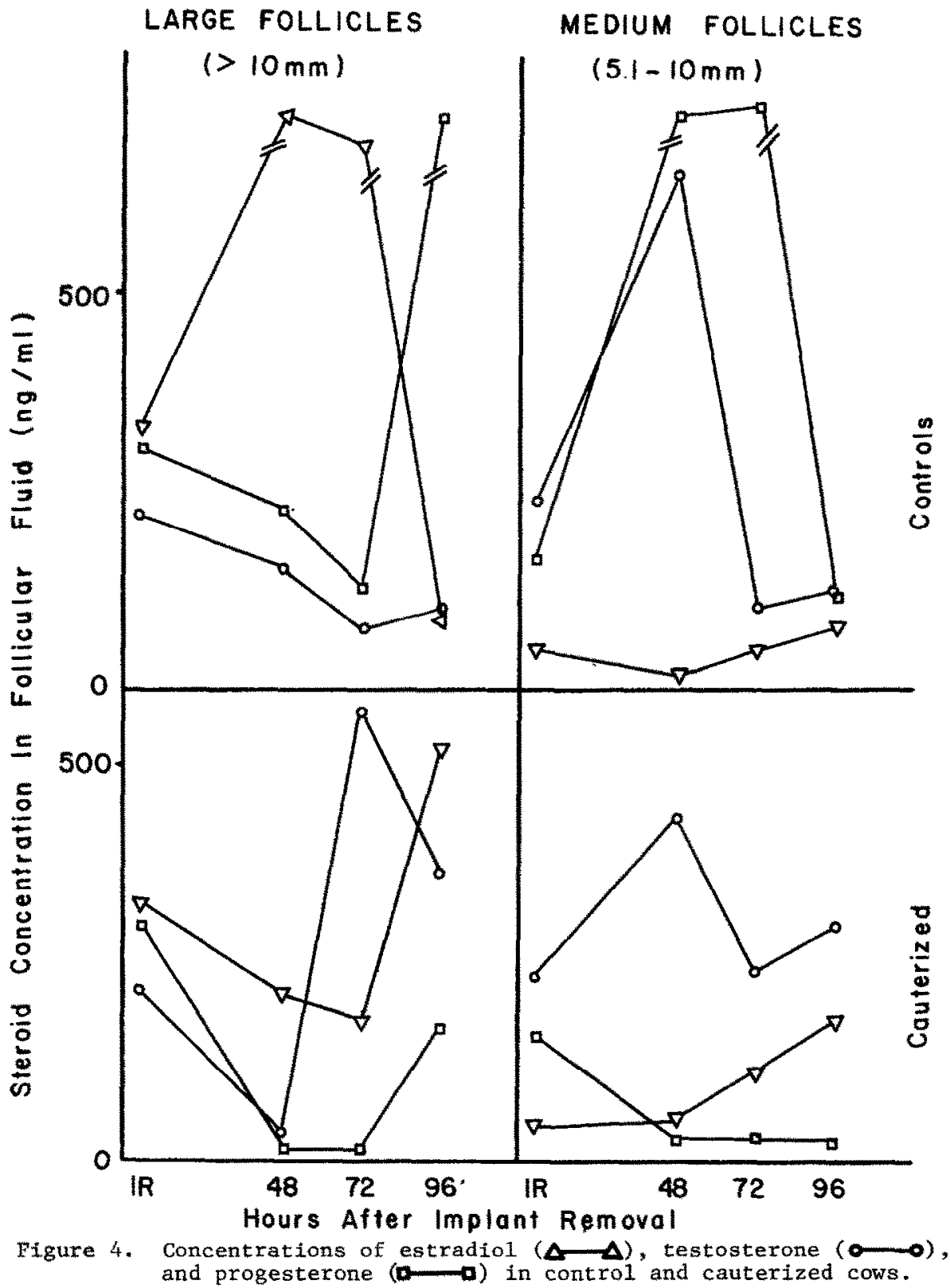




\section{THERIOGENOLOGY}

the point of being capable of ovulation. At $96 \mathrm{~h}$ following cautery, neither the slze of the largest follicle nor the estradiol production in the follicular fluid were indicative of a preovulatory follicle. It is significant, however, that in cauterized cows, some follicles in the upper end of the medium follicle size range ( 8 to $9 \mathrm{~mm}$ ) had concentrations of $E_{2}$ clearly higher than those follicles normally assoclated with that size classiffcation. Hence, with the proper stimulus, $E_{2}$ secretion can develop more rapidly than follicle size. This fact raises some important questions about how many follicles on the ovary at any one time are capable of being stimulated to ovulation, what is the minimum size that will respond, and is this size different at different stages of the cycle? Also of major concern for successful superovulation is a further understanding of the type of stimulus needed and the stage of the cycle at which the stimulus is required to develop ovulatory capabilities in more than a single follicle.

\section{Summary}

During the follicular phase of the estrous cycle in the cow, there is a rapid turnover in large (ovulatory size) follicles with the ovulatory follicle being 1dentifiable by size not more than 3 days prior to estrus. Characteristics of the ovulatory follicle have been described in terms of sterold production and, to a lesser extent, gonadotropin receptors. It remains yet to be determined which factors permit development of these characteristics rather than leading to the onset of atresia. 
1. Rajakoski, E. The ovarian follicular system in sexually mature heffers with special reference to seasonal, cyclical and leftright variations. Acta Endocrino1. (Suppl.) 52:1-68 (1960).

2. Choudary, J. B., Gier, J. T. and Marian, G. B. Cyclic changes in bovine vesicular follicles. J. Anim. Sci. 27:468-741 (1968).

3. Ireland, J. J., Conlson, P. B. and Murphee, R. L. Follicular development during four stages of the estrous cycle of beef cattle. J. Anim. Sci. 49:1261-1269 (1979).

4. Matton, P., Adelakoun, V., Couture, Y. and Dufour, J. J. Growth and replacement of the bovine ovarian follicles during the estrous cycle. J. Anim. Sci. 52:813-820 (1981).

5. Clark, J. R., Daily, R. A., Staigmiller, R. B., First, N. L., Chapman, A. B. and Casida, L. E. Observed associations between corpora lutea and follicular development in swine ovaries during the estrous cycle. J. Anim. Sc1. 41:1693-1699 (1975).

6. Dufour, J. J., Ginther, O. J. and Casida, L. E. Intraovarian relationships between corpora lutea and ovarian follicles in ewes. Amer. J. Vet. Res. 33:1445-1446 (1972).

7. Rexroad, C. E. and Casida, L. E. Ovarian follicular development in cows, sows and ewes in different stages of pregnancy as affected by number of corpora lutea on the same ovary. J. Anim. Sc1. 41:1090-1097 (1975).

8. Staigmiller, R. B., England, B. G., Webb, R., Short, R. E. and Bellows, R. A. Estrogen secretion and gonadotropin binding by individual bovine follicles during estrus. Endocrinology (submitted).

9. Moor, R. M. The ovarian follicle of the sheep: Inhtbition of oestrogen secretion by luteinizing hormone. J. Endocrinol. 61:455-463 (1974).

10. Webb, K. and England, B. G. Identification of the ovulatory follicle in the ewe: Associated changes in follicular size, thecal and granulosa cell LH receptors, antral fluid steroids and circulating hormones during the preovulatory period. Endocrinology (in press, 1981). 